\title{
Only seeing is believing - the power of evidence and reason
}

\section{Bernhard Rupp $p^{1,2, \bowtie}$}

${ }^{1}$ k.k. Hofkristallamt, 991 Audrey Place, Vista, CA, 92084, USA

${ }^{2}$ Department of Genetic Epidemiology, Medical University Innsbruck, Schöpfstr. 41, Innsbruck, A-6020, Austria

k.k. Hofkristallamt, 991 Audrey Place, Vista, CA, 92084, USA; e-mail: br@hofkristallamt.org

Received: May 6, 2016

Accepted: May 8, 2016

Key words: model interpretation, Bayesian inference, validation, scientific reasoning

Acknowledgements: This work was supported in part by the Austrian Science Foundation (FWF) under project P28395-B26 and by Crystallographiae Vindicis Militum Ordo, CVMO, k.-k. Hofkristallamt, San Diego, a non-profit organization for the promotion of reason.

\begin{abstract}
$\mathbf{B}^{\mathrm{i}}$ iomolecular crystallography is a mature science that provides an instructive example for modern inductive reasoning as a model for Bayesian epistemology in empirical science. Fundamental scientific epistemology requires that a strong claim is supported by strong and convincing proof. Biomolecular crystallography, based on solid foundations of rich experimental data and extensive prior knowledge provides a prime example for modern, evidence based reasoning that strongly relies on assessments of plausibility based on prior knowledge while at the same time constantly delivering some of the most novel and exciting results based on new experimental evidence. As a consequence of the solid underlying physical principles and its mathematical rigor, crystallography as a mature science could be almost fool proof - were it not for the human element.
\end{abstract}

\section{BIOMOLECULAR CRYSTALLOGRAPHY - THE POWER OF EVIDENCE AND OF REASONING}

The arguably most powerful instruments in Alexander Wlodawer's cornucopia of research tools is biomolecular crystallography. The results of his outstanding work on biomolecular structure have delivered deep insights in the molecular details of protein function and the machinery of cellular mechanisms. The question is, what makes the crystallography of biomolecules, mostly proteins - often in complex with small molecule therapeutic drugs, peptides and regulated DNA - such a powerful research tool?

Biomolecular crystallography is an experimental science - the term science being used here in contrast to simply experimental technique on purpose - and thus based on evidence. In the general biomedical sciences, experiments are seldom trivial as one is working with live cells, sensitive and easily degrading materials, and one often depends on sophisticated assays relying on materials and probes that are poorly defined [1]. In addition, the experimenter is not always aware of inherent limitations of the selected technique. The result is the poor reproducibility of a surprisingly large percentage of reported experimental findings in biomedical sciences [2]. In contrast, due to the solid underlying physical principles and its mathematical rigor, crystallography as a method could be almost fool proof - were it not for the human element.

In the following we shall first visit the foundations of biomolecular crystallography, point out its strength and weaknesses, and develop why it is such a prime example for modern, evidence based reasoning that strongly relies on assessments of plausibility based on prior knowledge, while at the same time constantly delivering some of the most novel and exciting results based on new experimental evidence.

\section{THE EXPERIMENT}

Crystallography is based on the simple fact that any periodic array of objects scatters, in a mathematically clearly defined manner, electromagnetic radiation of a wavelength comparable to the size of the scattering objects. In the case of molecules, the scattering objects are the electrons surrounding the atomic nuclei, with the size of an atom in the 1-2 Angstrom $(\AA)$ range. The wavelengths useable for diffraction therefore are also in the $\AA$ range (around $0.1 \mathrm{~nm}$, or $\sim 12 \mathrm{keV}$ on the energy scale). Radiation sources for such wavelengths are readily available, and most experiments are carried out now using sophisticated machinery - synchrotron sources - that produce tuneable hard X-ray radiation [3]. Therefore, the term X-ray crystallography.

\section{NO CRYSTALS - NO PROBLEM}

The periodic object upon which this X-ray radiation acts, is a crystal. In the case of proteins, these crystals are formed via self-assembly of protein molecules 
into a periodic crystal lattice. This process is non-trivial, and at present it cannot be predicted which conditions will lead to successful crystallization of a specific protein. Often thousands of trial and error experiments are conducted until a diffracting crystal is obtained. Because protein molecules are irregularly shaped and asymmetric, they generally pack loosely and their crystals are very fragile, sensitive to environmental changes, and contain a substantial amount $(50 \%$ on average) of the mother liquor or solvent they grew in [4].

While the requirement to form a highly regular assembly of about $10^{12}-10^{9}$ molecules indeed presents a significant challenge, the prerequisite to pack identical objects comes with a significant benefit. There are practically no problems caused by impure samples: Chemically impure and conformationally inhomogeneous samples almost never crystallize well. Even in the case of successful crystal growth, wherever non-homogeneity in the crystal exists, the diffraction experiment simply does not deliver interpretable evidence. Compare this to bioassays, where a small number of active molecules foreign species easily can produce an erroneous positive signal.

\section{ONE EXPERIMENT - 10,000s DATA POINTS}

Another fact that distinguishes biomolecular crystallography from other biomedical or biochemical techniques is that one successful diffraction experiment generally delivers anywhere between a few 10,000s to hundreds of thousands of data points. Figure 1 illustrates that from one single crystal an enormous number of diffracted X-rays emanate, whose intensity as 'reflections' or diffraction spots is readily measured with the aid of modern semiconductor-based X-ray area detectors. While a diffraction data set can be useless for a variety of reasons, there is no doubt that the experiment itself delivers a generous amount of quantitative observations. In contrast, biomedical assays are seldom repeated with high redundancy, and their complexity may invite selective interpretation of only positive results (cf. § "Human folly").

\section{WHEN MATHEMATICAL RIGOR....}

Figure 1 also imparts that we are not done simply with diffraction data collection. The diffraction data are obtained

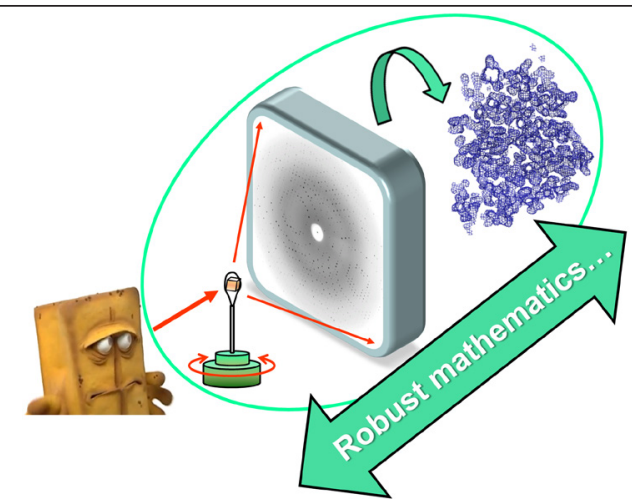

Figure 1. The diffraction experiment is conceptually simple. A rotating crystal is exposed to a brilliant X-ray beam, and a series of diffraction patterns is recorded on a 2D area detector. From the diffraction data and phase information, the electron density as the primary evidence is reconstructed. The entire process is technically non-trivial, but mathematically rigorous. Little opportunity for interpretative freedom exists at this stage. in a domain reciprocal to the real space humans reside in, and thus not interpretable with our senses. Fortunately, a mathematically rigorous and robust method, Fourier Synthesis, allows us to reconstruct the equivalent real space presentation of the diffraction data. As the electrons of the atoms are the physical source of diffraction, the reconstruction consequently reproduces the distribution of these electrons in 3D space, termed the electron density. If we plot this electron density at reasonable contour levels, we obtain an electron density map, exemplified by the blue mesh in figure 1 . This electron density presents our experimental evidence.

The path from diffraction data to electron density is a mathematically rigorous one. If there is local disorder in the crystal, then this disorder will lead to locally poor electron density. If the disorder in the crystal is systemic, the amount of diffraction data will be limited, and the electron density will reveal little detail, termed low resolution. Again, we are protected from producing incorrect evidence: If the data or reconstruction are poor, the evidence in form of the electron density will be equally poor. Garbage in, garbage out.

\section{....MEETS INTERPRETATIVE FREEDOM}

The process of crystallographic structure determination (unfortunately, one is tempted to say) does not stop at the electron density reconstruction. To represent the molecular structure as present in the crystal, an atomic model is built into the electron density. At this point, interpretative freedom enters the game, and were freedom is given, liberties are taken [5], which Alex Wlodawer and co-workers recently reminded us of [6]. An atomic model is simply a collection of atoms, each characterized in general by four adjustable parameters: the coordinates $\mathrm{x}, \mathrm{y}, \mathrm{z}$ determining its location, and a fourth, atomic displacement parameter $B$, which is in essence a measure of the probability of finding the atom at its stated position. This B-factor appears in the negative exponent in the structure factor summation giving rise to diffraction intensities, and therefore, a large B-factor means lower scattering contribution and (reciprocally) broad electron density peaks in real space.

It is very important to realize that the crystal structure itself is the reality; it consists of all matter in the crystal that gives rise to the diffraction pattern, including macromolecules, ligands, ordered and disordered solvent. The model we build into the electron density is not the crystal structure per se, it is only a limited presentation of the ordered parts of this crystal structure, conceivable as a hypothesis as to what the actual molecules might look like. This viewpoint as a testable hypothesis will become important later in the discussion.

An atomic structure model containing $n$ atoms always and invariably requires $4 n$ parameters for its description irrespective of how well the crystal diffracts (which affects how many data points can be collected), and consequently, how detailed the reconstructed electron density is. It is quite intuitive then that, the better the electron density represents the atomic detail, the more accurate the atomic model will be. On the other hand, with poor electron density, the placement of an atomic model can become extremely difficult. With poor electron density, unbiased automated model building programs tend to fail, and subjective interpretative 


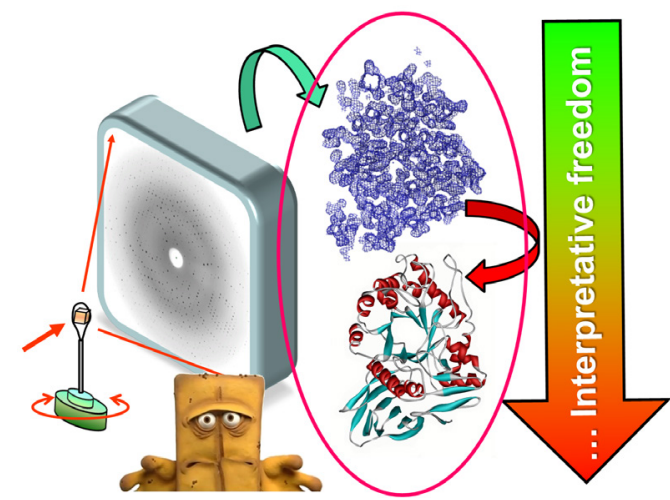

Figure 2. Electron density needs to be interpreted to obtain an atomic model of the macromolecule. If the electron density is poor, unbiased automated model building or ligand placing programs often fail, and ample opportunity for interpretative freedom and human folly enters the game.

freedom and individual desires may become the dominant factors in model building (Fig. 2).

Mathematically, the adjustment of the model parameters $\mathrm{x}, \mathrm{y}, \mathrm{z}$ and $\mathrm{B}$ for each atom by reciprocal space refinement (so that the calculated diffraction intensities match the observed ones), is in most instances severely underdetermined: Considering diffraction data only, not enough data points are available to optimize the $4 n$ atomic parameters with any accuracy. Except in rare instances of true atomic resolution data, no physically reasonable structural model of a protein molecule could ever be obtained based on interpretation of electron density and refinement against data alone.

\section{GREAT EXPECTATIONS}

"All other swindlers upon earth are nothing to the self-swindlers, and with such pretences did I cheat myself." - Charles Dickens, Great Expectations, 1861 [7]

As a result of the solid body of knowledge about the structure of matter gained by high resolution crystallography over the past 100 years [8], we have quite accurate expectations about the properties of a plausible protein structure model. Particularly the stereochemistry is well described, and bond lengths, bond angles, and preferred torsions as well as the chirality of the asymmetric centres are known. The incorporation of prior knowledge into the posterior probability of our model likelihood during reciprocal space refinement provides evidence-based models that at the same time maintain plausible physical properties. But the inclusion of prior evidence comes at a price: Our prior expectation, gained through averaging of large numbers of well-established instances (largely derived from accurately determined small molecule structures) can only be modified to reflect the individual new crystal structure by including strong evidence. The weaker the evidence, the more we must rely on prior knowledge, and the less we will learn about the specifics of our new molecule. In fact, a purely computational model can appear perfect as far as its stereochemistry is concerned, and at the same time bear no relevance to any reality. Any validation of such a model against expected stereochemistry will therefore reveal no problems - the curse of the restraints - making it clear that the inspection of the model against actual evidence - the electron density - is the most important safeguard for the creators as well as the users of crystallographic models. The need for local electron density inspection has long been recognized [9] and its importance for review has been re-emphasized [10] a decade ago.

What may surprise is that while from $\S 2.3$ we understand that without experimental data we simply cannot reconstruct the electron density, the need for public deposition of the experimental data became mandatory only in 2008. Even to this date, only the PDB validation reports are 'recommended reading' for reviewers, but no mandate exists to inspect the electron density for new structure model depositions. A related unresolved question is how to expunge demonstrably wrong models from the public data repositories, where they bias data mining and lead to invalid meta analyses [6]. Alex Wlodawer has also been at the forefront of opening the discussion on these unresolved and contentious issues [11,12].

\section{INDUCTIVE REASONING IN CRYSTALLOGRAPHY}

Modern biomolecular crystallography rests on two fundamental pillars: an enormously rich number of experimental data points - each single data set contains hundreds of thousands of individual observations, and a rich collection of expectations about how a healthy protein structure in general should look like. These facts allow for a sensible application of advanced, probability-based statistical inference methods. First, the large number of experimental data allows us to reliably apply the law of large numbers and the central limit theorem in the statistical analysis and processing of the data themselves. At the same time, the presence of a solid body of prior expectations allows us to keep our models in check with reality even in view of limited data. The formalism that allows to incorporate this line of reasoning - the weighting of new evidence against prior expectations - into a formal logical framework was introduced in the 1700s during the age of Enlightenment and the time of the establishment of the Royal Society in London. The original posthumous publication by Bayes [13] preceded the modern treatment by Laplace [14] in use today. In addition to the rules of formal reasoning, the interpretative freedom during the model building stage requires crystallographers to be also aware of: the concept of parsimony; the need to support extraordinary claims with extraordinary evidence; and not the least, to be aware of cognitive biases and postmodern excursions that may affect judgement.

The concept of Bayesian inference has penetrated the field of crystallography since its introduction in the late 1970s by Simon French [15] and by Gerard Bricogne in his Bayesian Programme in the early 1980s [16]. Its applications range from intensity measurement corrections [17] to phasing [18-21], density modification [22], model building [23], and to regularized maximum posterior likelihood refinement (also simplified as Maximum Likelihood refinement) of biomolecular structure models [24-26].

\section{EXAMPLES}

Negative diffraction intensities. One of the earliest and most intuitive examples for the application of Bayesian reasoning relates directly to data collection. In the diffraction exper- 
iment, we count the number of photons scattered in a specific direction, and express the number of counts as an intensity. In a perfect experiment, these intensities would always be positive numbers, but experimental errors can lead to negative values. The presence of negative intensity values poses a dilemma: We instinctively realize that it makes no sense to measure negative photon counts (either no diffraction occurs, or it does), and in addition, the downstream processing requires us to take the square root of the intensities. In the case of negative intensities a complex number results, promptly violating the physical principle that an observable of any quantum-mechanical process has to yield a scalar (simple number) value.

The question is what to do in this case. Simply throwing out the negative data omits valuable information that we possess (we are fairly certain that the intensity is at least not very high) and it does reek a bit of confirmation bias, namely using only data that fit our preconceptions. Bayes to the rescue: We have reasonable expectations how on average - properly based on a large number of events - diffraction intensities will be distributed [27]. Therefore, we can articulate a posterior likelihood by modifying this always positive expectation value in view of an observed negative intensity: A very high negative intensity would make it very unlikely that the actual value could be high, and at the same time, allows to assign a very high uncertainty to this value. The basics for Bayesian algorithms used today in the processing of negative intensity data have been introduced by French and Wilson in 1978 [17].

Restraining excessive freedom. It was pointed out in $\S$ "Great expectations" that a model built in real space in the electron density will have many correlated small errors in bond lengths, bond angles, planarity, or other stereochemical parameters which simply cannot be corrected due to insufficient detail in the electron density. To correct these errors, we employ regularized maximum posterior reciprocal space refinement against a squared likelihood residual that includes our prior expectations of reasonable stereochemistry. While this sounds complicated, in effect we are simply limiting excessive freedom of our model, while at the same time allowing for errors and incompleteness in our model.

\section{THE EPISTEMOLOGICAL MACHINERY}

The embedment of our inductive inference problem into a formal probabilistic framework is provided by Bayes' Theorem. It can be derived directly from the product rules for joint independent probabilities [28-30]. In terms of model $(M)$ and data $(D)$

$$
\operatorname{prob}(M \mid D)=\frac{\operatorname{prob}(D \mid M) \times \operatorname{prob}(M)}{\operatorname{prob}(D)}
$$

The sought-after posterior model likelihood $\operatorname{prob}(M \mid D)$ is the joint probability of the (data) likelihood function $\operatorname{prob}(D \mid M)$ (which can be more or less readily calculated given the model) and the prior probability of our model prob(M) gained independently of the actual data. The denominator $\operatorname{prob}(D)$ takes on different forms, depending on what we intend to use Bayes' theorem for. If we apply Bayes' theorem to hypothesis testing or if we are interested in absolute values, it becomes a marginalization term as the sum of probabilities of all alternate hypotheses. In the case of parameter estimation, we can simply absorb it in a proportionality constant, because the maximum of a likelihood function remains at the same optimal parameter vector irrespective of its absolute value. The Bayes' formula then simplifies to:

$$
\operatorname{prob}(M \mid D) \propto \operatorname{prob}(D \mid M) \times \operatorname{prob}(M)
$$

Maximizing $\operatorname{prob}(D \mid M)$ by adjusting the model parameters also maximizes our posterior likelihood and thus provides the best model. This is the basis of Maximum Likelihood Methods in crystallography. Because we also include deviations from the expected geometry in the optimization target function, the procedure is in fact a regularized maximum posterior (likelihood) refinement. Note that the quest for the optimal set of parameters for a given parameterization of a model is not the same as the quest for the best model (which may be differently parameterized). The former is a question of minimization, but the second one is one of hypothesis testing, generally examined via a likelihood (or Bayes) ratio of competing hypotheses.

Bayesian reasoning. Examination of (2) imparts an important observation: In order to achieve maximal posterior probability of our model, solid evidence (meaning that our model reproduces the data well) combined with reasonable compliance with already established facts are optimal. At the same time, we realize that if our evidence is weak, we must rely heavily on the prior expectations, while vice versa to overcome ingrained prior expectations, our evidence term needs to be very strong; in other words, a strong claim needs comparably strong evidence. As a practical example, take the claim of a specific location and conformation of a ligand molecule in a protein structure: This specific pose is just one of many competing hypotheses of possible locations and conformations, and there better be strong evidence in form of electron density for that ligand (Fig. 3 ). The most definite proof for a ligand is unbiased positive omit difference density. That not all is well in macromolecular crystallography as far as evidence for plausible ligands is concerned has been recently shown [31].

The interpretation of the data likelihood function $\operatorname{prob}(D \mid M)$ as a modifier for our prior belief for a hypothesis (or, in our structure, model $M$ ) reveals another important aspect of Bayesian inference: Any model that fundamentally contradicts prior knowledge will have to provide very convincing and solid experimental evidence to persuade us to accept it as probable and eventually change our generally well established prior perceptions. An excellent example is the crystallographic determination of the, until then considered impossible, 4-membered lactam ring structures by Dorothy Hodgkin [34]. Convincing and reproducible evidence is the means by which science eventually corrects its own misperceptions [35]. Weak data will not overcome a strong prior probability or knowledge, but a strong experiment can either modify or affirm our prior beliefs. An excursion into Thomas S. Kuhn's The Structure of Scientific Revolutions may be suggested further reading [35].

Parsimony and cross-validation. The principle of parsimony or the 'law of succinctness' commends selecting a model or hypothesis that postulates as few parameters as possible, there- 


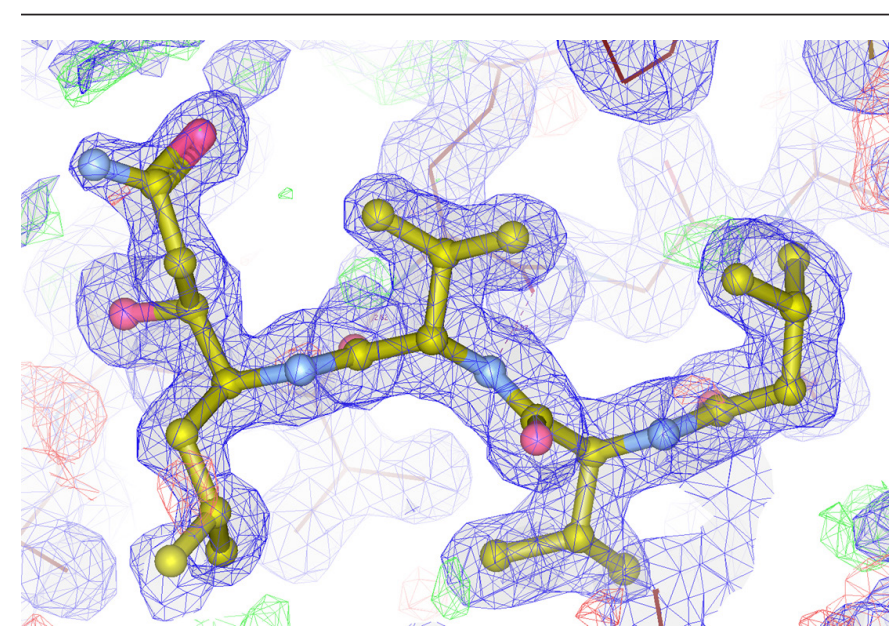

Figure 3. A peptide inhibitor with optimal fit to electron density. The figure shows the peptide inhibitor pepstatin A (ball and stick model) bound to a retroviral protease in clear electron density (blue grid), contoured at a $2 m \mathrm{~F}-D \mathrm{~F}_{c}$ electron density level of 1 sigma (PDB entry $3 \mathrm{sm} 1$, chain J, by Alexander Wlodawer and coworkers [32]). There is (i) no doubt about the presence and pose of the inhibitor, (ii) the peptide inhibitor assumes a stereochemically plausible conformation, and (iii) no steric clashes or implausible interactions with the protease are indicated. Positive omit difference density practically overlaps with the displayed density. The image was prepared using the model building graphics program Coot [33] displaying the $2 m \mathrm{~F}_{0}-D \mathrm{~F}_{c}$ electron density map reconstructed from maximum likelihood coefficients computed by the refinement program Refmac [26].

by eliminating unnecessary variables that make no significant difference in the fit of the model (or an explanatory hypothesis) to the data. This basic idea dates back to the English logician and Franciscan friar William of Ockham (1288-1347, Occam in Latin spelling) and is known as Occam's razor: "Numquam ponenda est pluralitas sine necessitate", or "Multitude must never be proposed without necessity". In formal terms, Occam's rule can be derived via the Bayesian formalism: A hypothesis with fewer adjustable parameters will automatically have an increased posterior probability [36].

For the highly multi-parametric models of biomolecular structures, the question arises as to when does a model become non-parsimonious? One statistical method much used in machine learning is to set aside a small cross-validation test data set that is excluded from refinement. As long as introduction of adjustable refinement parameters improves both the fit of the model to the working data set as well as the fit to the test data set, the parameter choice can be justified. This introduction of R-free [37] helped to (slowly) convince crystallographers that indiscriminately throwing solvent molecules in any spurious density peaks leads only to non-parsimonious overfitting but not to a better model. Similar crossvalidation exists in real space through omit maps [38,39] (where a small part of the model, or ligand in question, is omitted from refinement before calculation of the Fourier coefficients). Positive difference omit maps are the golden standard for proof of the presence of a ligand in a complex structure [31]. The fact that peptide torsion angles are important non-restrained stereochemical parameters with a high degree of freedom but with well-defined prior distributions, renders them an ideal geometric real space cross-validation test set. Particularly in peptide ligand structures, backbone conformations have been published that can be charitably described only as delusional [40-42], as exemplified in figure 4 .

\section{HUMAN FOLLY}

With all the advanced automated data collection, advanced probabilistic computational crystallography programs, and copious validation tools, one wonders why some investigators still and with great apparent enthusiasm, deposit models of ligands in absence of credible electron density support, and often of implausible conformations (Fig. 4). A lack of technical competence is almost certainly a contributing factor, but cognitive bias seems to be the real and more fundamental problem, as suggested early on by various critical voices $[5,9,43]$ and recently emphasized by Alexander Wlodawer and co-workers $[6,12,44,45]$.

That "the human understanding is not composed of dry light, but is subject to influence from the will and the emotions, a fact that creates fanciful knowledge; man prefers to believe what he wants to be true" is not a new insight $[49,50]$. Francis Bacon's above statement published originally in 1620 reminds us that wishful thinking and self-deception in the course of electron density interpretation are, next to poor training and negligence, perhaps the most common reasons for the creation of flawed structure models. Seeing spurious density as evidence for the presence of a ligand is known as confirmation bias, while the ignorance of warning signs such as adverse real space correlation of distorted geometry (or not even conducting validation or reading validation reports) constitutes a form of expectation bias [51]. Even the editors of scientific vanity journals have only recently (apparently as victims of expectation bias themselves)

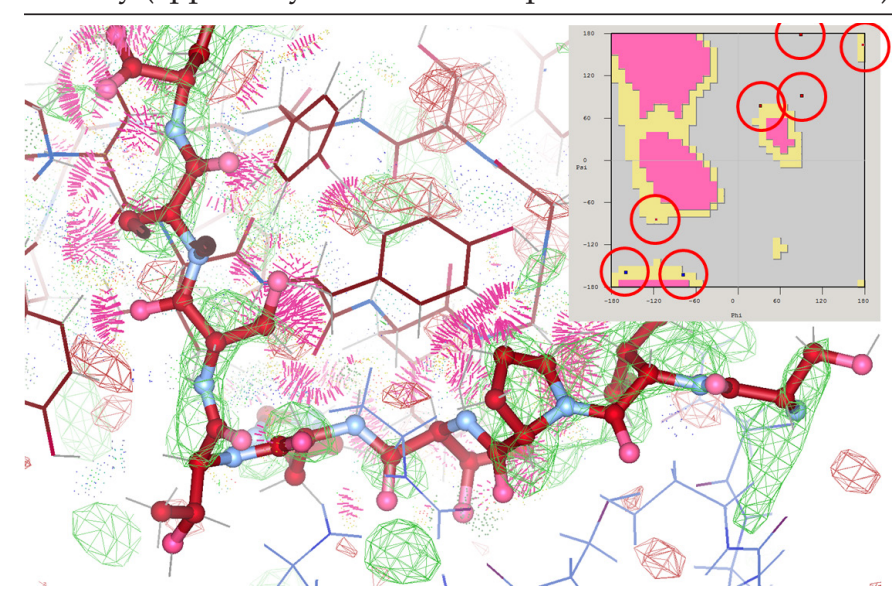

Figure 4. An improbable peptide ligand. The main figure shows a model of a peptide antigen (ball and stick model) bound to an Fab antibody fragment (thin sticks), together with its positive $m \mathrm{~F}_{0}-D \mathrm{~F}_{c}$ omit difference density, meaning that the ligand was omitted during maximum likelihood difference electron density map calculation. The peptide model should be surrounded by clear difference density (green mesh, contoured at 2.5 sigma above mean noise level) resembling its distinct shape. There are only discontinuous fragments visible, which in part can be explained by ordered solvent (the round green spheres are typical of water molecules). In addition to (i) not being placed in any recognizable electron density, the antigen model (ii) has a multitude of unreasonably close contacts (steric clashes, visualized as the nasty red spikes) with the antibody fragment, and (iii) has an utterly implausible high energy backbone conformation, as evidenced by finding all the backbone $\varphi / \psi$ torsion angle pairs (circled) in unfavourable regions of the Ramachandran plot (top right insert). The combination of absence of primary evidence together with violation of any established prior expectations preclude the presence of this modelled peptide in the crystal structure (PDB entry 2a6i, chain $\mathrm{P},[46])$. The publication citing this model as evidence has been lauded in an editorial [47] and cited 67 times in Scopus. None of this speaks for the quality of the associated peer review and editorial stewardship. The image was prepared using the model building graphics program $\operatorname{Coot}[33]$ displaying the $m \mathrm{~F}-D \mathrm{~F}$ map reconstructed from maximum likelihood coefficients computed by the refinement program Refmac [26]. The backbone torsion angles and interatomic clashes were calculated with the MolProbity suite [48]. 
woken up to the manifestation of human factors clouding their inferential reasoning [52]. That editors (and reviewers) accept papers based on newsworthiness instead of high Bayesian degree of belief, is a primary reason for data base contamination. Jonathan Swift, another contemporary of the Enlightenment, succinctly states: "Falsehood flies, and truth comes limping after it, so that when men come to be undeceived, it is too late; the jest is over, and the tale hath had its effect" [53].

\section{POSTMODERN ABERRATIONS: TO ERR IS HUMAN, TO REALIZE IT IS DIVINE}

A contributing factor to the ignorance of the basics of inductive inference, which have served us well since the Enlightenment, is the subtle creep of postmodernism into the scientific curriculum. Allen Sokal, author of an infamous hoax in Social Text [54] defines postmodernism as "An intellectual current characterized by the more-or-less explicit rejection of the rationalist tradition of the Enlightenment; by theoretical discourses disconnected from any empirical test; and by a cognitive and cultural relativism that regards science as nothing more than a narration, myth or a social construct among many others". In response to members of the open minded crowd inclined towards model building anarchy, who often like to misquote from Against Method [55], one might suggest a helpful amended quote: "Anything goes as long as you do not know what you are doing".

Analysis of spurious evidence in fact provides one with an enormous amount of interpretative freedom. The outcome in general is what is well described as fringe science [56]: "The first characteristic of pathological science is that the effect being studied is often at the limits of detectability or has very low statistical significance.". In defence of hypotheses based on weak evidence, arguments such as the following may be voiced: "In my scientific pursuit, I develop and follow a hypothesis until it has been proven to be flawed, and I have not reached that point at all with this study." This argument - essentially an abuse of Karl Popper's falsification requirement [57], however 'open-minded' it may sound - is deeply flawed. The point of Bayesian inference - which actually and effectively guides us in everyday life as it does in scientific review - is exactly that not every outlandish hypothesis (e.g. being able to walk through walls) must be pursued each time until falsification. In a similar fashion, fringe scientists, UFO acolytes, and other transcendentalists provide the argument that "The absence of evidence is not the evidence of absence". Bayes of course clobbers this equally superficially open-minded argument, which ignores any prior probability terms: The crucial difference between the absence of a fossil find in an evolutionary sequence and the absence of UFO remnants is the strikingly different level of prior probability. In the same sense, prior knowledge dictates that discrete features of a crystallographic model must be associated with clear evidence of electron density. The final conclusion then, distilling our entire discourse into a single sentence at the core of crystallographic reasoning simply reads: Absence of electron density is evidence of absence.

\section{FINAL REMARKS}

Macromolecular crystallography has in almost unprecedented ways provided the basis for defining the detailed molecular mechanisms and interactions of biological pro- cesses. Future biological sciences will progress from the basis of these established building blocks to an interconnected synergetic view of biological systems - but only if the underlying models of these processes are based on solid evidence. Alexander Wlodower's work in biomolecular crystallography has greatly contributed towards this goal. Best wishes on your $70^{\text {th }}$ birthday, Alex.

\section{REFERENCES}

1. Freedman LP, Cockburn IM, Simcoe TS (2015) The economics of reproducibility in preclinical research. PLoS Biol 13: e1002165

2. Collins FS, Tabak LA (2014) Policy: NIH plans to enhance reproducibility. Nature 505: 612-613

3. Helliwell JR, Mitchell EP (2015) Synchrotron radiation macromolecular crystallography: science and spin-offs. IUCrJ 2: 283-291

4. Weichenberger CX, Afonine PV, Kantardjieff K, Rupp B (2015) The solvent component of macromolecular crystals. Acta Crystallogr D71: 1023-1038

5. Kleywegt GJ, Jones TA (1995) Where freedom is given, liberties are taken. Structure 3: 535-540

6. Raczynska JE, Wlodawer A, Jaskolski M (2016) Prior knowledge or freedom of interpretation? A critical look at a recently published classification of "novel" Zn binding sites. Proteins 84: 770-776

7. Dickens C (1861) Great Expectations. Chapman and Hall, London.

8. Garman EF (2014) Developments in X-ray crystallographic structure determination of biological macromolecules. Science 343: 1102-1108

9. Brändén CI, Jones TA (1990) Between objectivity and subjectivity. Nature 343: 687-689

10. Rupp B (2006) Real-space solution to the problem of full disclosure. Nature 444: 817

11. Dauter Z, Wlodawer A, Minor W, Jaskolski M, Rupp B (2014) Avoidable errors in deposited macromolecular structures: an impediment to efficient data mining. IUCrJ 1: 179-193

12. Minor W, Dauter Z, Helliwell JR, Jaskolski M, Wlodawer A (2016) Safeguarding structural data repositories against bad apples. Structure 24: $216-220$

13. Bayes $\mathrm{T}$ (1763) An essay towards solving a problem in the doctrine of chances. Phil Trans Roy Soc 53: 370-418

14. Laplace PS (1814) Essai philosophique sur les probabilités, Paris Bachelier, Paris

15. French S (1978) A Bayesian three-stage model in crystallography, Acta Crystallogr A34: 728-738

16. Bricogne G (1997) Bayesian statistical viewpoint on structure determination: Basic concepts and examples. Methods Enzymol 276: 361-423

17. French S, Wilson K (1978) On the treatment of negative intensity observations. Acta Crystallogr A34: 517-525

18. Terwilliger TC, Berendzen J (1997) Bayesian correlated MAD phasing. Acta Crystallogr D53: 571-579

19. Bricogne G (1988) A Bayesian statistical theory of the phase problem. I. A multichannel maximum-entropy formalism for constructing generalized joint probability distributions of structure factors. Acta Crystallogr A44: 517-545

20. Terwilliger T (1994) MAD phasing: Bayesian estimates of FA. Acta Crystallogr D50: 11-16

21. McCoy AJ, Grosse-Kunstleve RW, Adams PD, Winn MD, Storoni LC, Read RJ (2007) Phaser crystallographic software. J Appl Crystallogr 40: 658-674

22. Terwilliger TC (1999) Reciprocal space solvent flattening. Acta Crystallogr. D55: 1863-1871

23. Terwilliger TC (2000) Maximum likelihood density modification. Acta Crystallogr D56: 965-972

24. Read RJ (1986) Improved Fourier coefficients for maps using phases from partial structures with errors. Acta Crystallogr A42: 140-149 
25. Smart OS, Womack TO, Flensburg C, Keller P, Paciorek W, Sharff A, Vonrhein C, Bricogne G (2011) Better ligand representation in BUSTER protein-complex structure determination. Acta Crystallogr A67: C134

26. Murshudov GN, Skubak P, Lebedev AA, Pannu NS, Steiner RA, Nicholls RA, Winn MD, Long F, Vagin AA (2011) REFMAC5 for the refinement of macromolecular crystal structures. Acta Crystallogr D67: 355-67

27. Wilson AJC (1949) The probability distribution of X-ray intensities. Acta Crystallogr 2: 318-321

28. Jaynes ET (2003) Probability Theory: The Logic of Science. Cambridge University Press Cambridge, UK

29. Edwards AWF (1992) Likelihood - An Account of the Statistical Concept of Likelihood and Its Application to Scientific Inference. Expanded edition edn, The Johns Hopkins University Press, Baltimore, MD

30. Rupp B (2010) Biomolecular Crystallography: Principles, Practice, and Application to Structural Biology. 2nd edn, Garland Science

31. Pozharski E, Weichenberger CX, Rupp B (2013) Techniques, tools and best practices for ligand electron-density analysis and results from their application to deposited crystal structures. Acta Crystallogr D69: 150-167

32. Li M, Gustchina A, Matuz K, Tozser J, Namwong S, Goldfarb NE, Dunn BM, Wlodawer A (2011) Structural and biochemical characterization of the inhibitor complexes of xenotropic murine leukemia virus-related virus protease. FEBS J 278: 4413-4424

33. Debreczeni JÉ, Emsley P (2012) Handling ligands with Coot. Acta Crystallogr D68: 425-430

34. Glusker JP (1994) Dorothy Crowfoot Hodgkin (1910-1994). Protein Sci 3: $2465-2469$

35. Kuhn TS (1970) The Structure of Scientific Revolutions. 2nd edn, University of Chicago Press, Chicago, IL.

36. Jefferys WH, Berger JO (1991) Sharpening Ockham's razor on a Bayesian strop, American Scientist 80: 64-72

37. Brunger AT (1992) Free R value: A novel statistical quantity for assessing the accuracy of crystal structures. Nature 355: 472-475

38. Bhat TN (1988) Calculation of an OMIT map. J Appl Crystallogr 21: 279-281

39. Terwilliger TC, Grosse-Kunstleve RW, Afonine PV, Moriarty NW, Adams PD, Read RJ, Zwart PH, Hung LW (2008) Iterative-build OMIT maps: map improvement by iterative model building and refinement without model bias. Acta Crystallogr D64: 515-524

40. Stanfield RL, Pozharski E, Rupp B (2016) Additional comment on three X-ray crystal structure papers. J Immunology 196: 528-530
41. Stanfield RL, Pozharski E, Rupp B (2016) Comment on three X-ray crystal structure papers. J Immunology 196: 521-524

42. Weichenberger C, Pozharski E, Rupp B (2016) Twilight reloaded: the peptide experience. Acta Crystallogr D72: submitted

43. Rupp B (2008) Scientific inquiry and inference in macromolecular crystallography. Acta Crystallogr A64: C81

44. Wlodawer A, Minor W, Dauter Z, Jaskolski M (2013) Protein crystallography for aspiring crystallographers or how to avoid pitfalls and traps in macromolecular structure determination. The FEBS J 280: 5705-5736

45. Dauter Z, Wlodawer A, Minor W, Jaskolski M, Rupp B (2014) Avoidable errors in deposited macromolecular structures: an impediment to efficient data mining. IUCrJ 1: 179-193

46. Sethi DK, Agarwal A, Manivel V, Rao KVS, Salunke DM (2006) Differential epitope positioning within the germline antibody paratope enhances promiscuity in the primary immune response. Immunity 24 : 429-438

47. Mariuzza RA (2006) Multiple paths to multispecificity. Immunity 24: 359-361

48. Chen VB, Arendall WB, III, Headd JJ, Keedy DA, Immormino RM, Kapral GJ, Murray LW, Richardson JS, Richardson DC (2010) MolProbity: all-atom structure validation for macromolecular crystallography. Acta Crystallogr D66: 12-21

49. Bacon F (1620) Novum Organum Scientarium; Partis Secundae Summa, Digesta in Aphorismos, Aphorismus XLIX

50. Bacon F (2000) The New Organon; Aphorism 49, Jardine, L. \& Silverthorne, M., Cambridge University Press, Cambridge, UK

51. Koehler JJ (1993) The influence of prior beliefs on scientific judgments of evidence quality. Organizational Behavior \& Human Decision Processes 56: 28-55

52. Editorial (2015) Let's think about cognitive bias. Nature 526: 163

53. Swift J (1710) The art of political lying. The Examiner. 17, November 9

54. Sokal AD (1996) Transgressing the Boundaries: Toward a Transformative Hermeneutics of Quantum Gravity. Social Text, 217-252

55. Feyerabend PK (1975) Against method: outline of an anarchistic theory of knowledge. New Left Books, New York

56. Langmuir I, Hall RN (1989) Pathological science. Phys Today 42: 36-48

57. Popper K (2002) The logic of scientific discovery. $14^{\text {th }}$ printing edn, Routledge, New York, NY

\section{Uwierzyć znaczy zobaczyć - o sile i konieczności rozumowania opartego na faktach}

\section{Bernhard Rupp ${ }^{1,2, \mathbb{}}$}

${ }^{1}$ k.k. Hofkristallamt, 991 Audrey Place, Vista, CA, 92084, USA

${ }^{2}$ Department of Genetic Epidemiology, Medical University Innsbruck, Schöpfstr. 41, Innsbruck, A-6020, Austria

e-mail: br@hofkristallamt.org

Słowa kluczowe: interpretacja modelu, wnioskowanie Bayesa, walidacja, rozumowanie naukowe

\section{STRESZCZENIE}

Krystalografia makromolekuł to bardzo dojrzała dziedzina naukowa, która dostarcza nam pouczającego przykładu nowoczesnego rozumowania indukcyjnego i modelowego zastosowania epistemologii Bayesowskiej w naukach doświadczalnych. Zgodnie z podstawowymi założeniami teorii poznania, radykalna teza musi być poparta mocnym i wiarygodnym dowodem. Krystalografia makromolekuł opiera się na mocnych fundamentach - solidnych i bogatych danych doświadczalnych oraz szerokiej, uprzedniej wiedzy badacza. Dzięki temu stanowi idealny przykład nowoczesnego rozumowania opartego na faktach oraz w znacznym stopniu bazującego na ocenie wiarogodności stawianych tez na podstawie posiadanej już wiedzy. Jednocześnie, dziedzina ta stale dostarcza nam przełomowych, nieoczekiwanych wyników wyłaniających się z nowych obserwacji doświadczalnych. Krystalografia dzięki leżącym u jej podstaw prawom fizycznym oraz matematycznej ścisłości, mogłaby być nieomylna, gdyby nie czynnik ludzki. 